\title{
Memory transfer vs. sensitization in cannibal planarians
}

\author{
D. R. WALKER ${ }^{1}$ AND G. A. MILTON \\ UNIVERSITY OF VICTORIA
}

Naive planarians were fed planarians which had been subject to varying amounts of electric shock but no light-shock conditioning. A positive relationship was found between the amount of shock received by the cannibalized planarians and the light conditioned responses of the cannibals. This is in terpreted as supporting a tissue sensitization hypothesis, rather than a memory transfer hypothesis.

Although McConnell (1962) and his colleagues have interpreted the positive effects on the response levels of naive planarians, after the ingestion of light-shock "conditioned" planarians, as memory transfer, a number of considerations indicate that this is not a parsimonious interpretation of the "cannibalism" results. First, Jensen (1965, p. 14) has demonstrated that the "conditioned" planarians are probably instances of pseudo-learning, and that many confounding variables affect conditioning studies in lower organisms. This is further supported by the demonstration of subtle effects of electric shock on the responses of planarians (Barnes \& Katzung, 1963). The lack of a cannibal-shock-control group (CSC) makes evaluation of McConnell's results difficult, but when the authors compared a CSC group with the experimental-cannibal (XC) group, they found that the CSC group, in fact, emitted more conditioned responses (CR) than did the XC group in 150 conditioning trials (Walker, 1963). Hartry, Keith-Lee, \& Morton (1964) found that their CSC group reached criterion faster than a group of naive control (CO) worms, but not as rapidly as their XC group.

These considerations suggest an alternative to McConnell's memory transfer hypotheses. The increased responsitivity of the cannibal planarians may be due to increased sensitivity to the experimental variables, due to the ingestion of tissue which had been shocked, rather than memory due to ingestion of tissue which had a conditioned association between the experimental variables. Sensitivity or sensitization as used in the present study refers to a non-associative physiological process, such as a lowering of receptor thresholds. This sensitization hypothesis leads to the prediction tested in the present study: that the number of conditioned responses made by cannibal worms is a positive function of the number of electric shocks given to the cannibalized worm.

\section{Method}

The Ss were 40 native planarians ${ }^{2}$ which were placed in individual aquariums 10 days before experimentation. Ss were maintained under constant illumination at $70^{\circ} \mathrm{F}$, in water which was changed bi-daily and were fed fresh liver until the beginning of the experiment. A twotrough apparatus, similar to that of McConnell, was used in the experiment. The unconditioned stimulus (US) was $.280 \mathrm{ma}$ dc delivered to the trough from a CJA 250 stimulator. Stimulus duration and inter-stimulus interval were controlled by Hunter interval timers. The conditioned stimulus (CS) was delivered from 100 w bulbs in four gooseneck lamps, two over each trough, 10 in. above the trough.

The $40 \mathrm{Ss}$ were randomly assigned to 10 groups of four Ss each. Five groups were cannibalized and five groups were cannibals. Four of the cannibalized groups were administered $.280 \mathrm{ma}$ dc shock every 30 sec. in blocks of 50 trials per day; group 50 received 50 shocks, group 100 received 100 shocks, group 150 received 150 shocks and group 200 received 200 shocks. Because planarians in this laboratory were never observed to attack, kill and devour another living planarian, the tobe-cannibalized Ss were killed by dehydration immediately after they had received the appropriate number of shocks. One hour after they were killed the cannibalized Ss were fed whole to the cannibals. Four Ss in group 0 received no shock and were fed to the cannibals after 10 days' isolation in individual containers. All feeding took place in the cannibals' home acquarium.

Ss in group C0 consumed group 0; group C50 consumed group 50; group C100 consumed group 100; group C150 consumed group 150 and group C200 consumed group 200. Twenty-four hours after feeding the cannibals received 25 conditioning trials consisting of paired light and shock. Conditioning continued for two more days with 25 trials given per day.

The CS (light) appeared for 3 sec. and the US (shock) appeared during the terminal $1 \mathrm{sec}$. of light. Conditioned responses were recorded during the initial $2 \mathrm{sec}$. of the CS. The intertrial interval was $30 \mathrm{sec}$. Ss were coded by number so that $\mathrm{E}$ was not aware from which group they came. ${ }^{3}$

Two possible responses were counted as CRs. These were: (1) a sharp right or left movement of the cephalic region; and (2) a longitudinal contraction of the entire body. These two responses were chosen because they provide the greatest inter-scorer reliability $(95 \%$ Agreement). A CR was recorded if either one of these two responses occurred during the $2 \mathrm{sec}$. of light prior to onset of the shock.

Results and Discussion

Table 1 presents the mean and standard deviation of the number of CRs made in 75 trials by the five groups of cannibals. Analysis of variance of these 
Table 1. Mean and Standard Deviation of the Number of CRs for the Five Groups of Cannibals in 75 Trials

\begin{tabular}{llll} 
Group & N & Mean & S.D. \\
\hline C0 & 4 & 18.00 & 5.48 \\
C50 & 4 & 18.75 & 6.40 \\
C100 & 4 & 24.00 & 5.51 \\
C150 & 4 & 24.50 & 4.80 \\
C200 & 4 & 29.50 & 2.65 \\
\hline
\end{tabular}

results is statistically significant $(F=3.37, d f=4 / 15$, $\mathrm{p}<.05)$ as are the comparisons $\mathrm{CO}+\mathrm{C} 50: \mathrm{C} 100+\mathrm{C} 150$ $(\mathrm{F}=5.17, \mathrm{df}=1 / 14, \mathrm{p}<.05)$ and $\mathrm{C100}+\mathrm{C} 150: \mathrm{C} 200(\mathrm{~F}=$ 4.04, $\mathrm{df}=1 / 10, \mathrm{p}=.05)$. The apparent differences among the standard deviations are not statistically reliable (Cochran's $\mathrm{C}=.45, \mathrm{df}=5 / 3, \mathrm{p}>.05$ ).

It is clear from these results that the number of shocks given to the cannibalized worms is an extremely important variable affecting the responsivity of the cannibals. There appear to be critical shock frequencies, between 50 and 100 and between 150 and 200, which are not readily explainable. The critical importance of these results is that they support a sensitization hypothesis, that a tissue change occurs due solely to shock which affects the sensitivity to the experimental variables, rather than a conditioned association between these variables. The memory transfer hypothesis of McConnell could not account for these apparent "savings" since the cannibalized worms were never exposed to differential light-shock pairings.

\section{References}

Barnes, C. D., \& Katzung, B. G. Stimulus polarity and conditioning in planaria. Science, 1963, 141, 728-730.

Hartry, A. L., Keith-Lee, P., \& Morton., W. D. Planaria: memory transfer through cannibalism re-examined. Science, 1964, 146, 274-275.

Jensen, D. D. Paramecia, planaria, and pseudo-learning. Animal Behaviour Supplement I, 1965, 9-20.

McConnell, J. V. Memory transfer through cannibalism in planaria. J. Neuropsychiat., 1962, 3, 45 .

Walker, D. R. A replication of studies on the effect of ingestion of conditioned planaria on the response level of naive planaria with added controls. Unpublished Honors Thesis, University of Victoria, 1963.

\section{Notes}

1. Present address, Department of Psychology, University of Iowa. 2. Northwest Biological Supply, Victoria, B. C.

3. Mr. Ben Sills participated as E. 